Article

\title{
A model to predict upstaging to invasive carcinoma in patients preoperatively diagnosed with low-grade ductal carcinoma in situ of the breast
}

\author{
Luca Nicosia 1", Anna Carla Bozzini 1, Silvia Penco 1, Chiara Trentin 1, Maria Pizzamiglio 1, Matteo Lazzeroni 2, \\ Germana Lissidini ${ }^{3}$, Paolo Veronesi ${ }^{3}$, Gabriel Farante ${ }^{3}$, Samuele Frassoni ${ }^{4}$, Vincenzo Bagnardi ${ }^{4}$, Cristiana Fodor ${ }^{5}$ \\ , Nicola Fusco ${ }^{6-7}$, Elham Sajjadi ${ }^{6-7}$, Enrico Cassano ${ }^{1^{* *}}$ and Filippo Pesapane ${ }^{1^{* *},}$
}

1 Breast Imaging Division, Radiology Department, IEO European Institute of Oncology IRCCS, 20141 Milan, Italy; luca.nicosia@ieo.it (L.N.); anna.bozzini@ieo.it (A.B.); silvia.penco@ieo.it (S.P.); chiara.trentin@ieo.it (C.T.); maria.pizzamiglio@ieo.it (M.P.); enrico.cassano@ieo.it (E.C.); filippo.pesapane@ieo.it (F.P).

2 Division of Cancer Prevention and Genetics, IEO European Institute of Oncology IRCCS, Milan; matteo.lazzeroni@ieo.it (M.L)

3 Division of Breast Surgery, European Institute of Oncology, IRCCS, Milan, Italy; germana.lissidini@ieo.it (G.L); paolo.veronesi@ieo.it (P.V); gabriel.farante@ieo.it (G.F);

4 Department of Statistics and Quantitative Methods, University of Milan-Bicocca, 20126 Milan, Italy. vincenzo.bagnardi@ieo.it (V.B.); samuele.frassoni@unimib.it (S.F.)

5 Division of Radiation Oncology, IEO, European Institute of Oncology IRCCS, Milan, Italy, cristiana.fodor@ieo.it (C.F)

6 Division of Pathology, IEO, European Institute of Oncology IRCSS, Milan, Italy

7 Department of Oncology and Hemato-Oncology, University of Milan, Milan, Italy, nicola.fusco@ieo.it (N.F), elham.sajjadi@ieo.it (E.S)

* Correspondence: luca.nicosia@ieo.it

** Those authors share senior authorship

Simple Summary: Surgical management is currently the main standard of care procedure used in order to treat ductal carcinoma in situ (DCIS) of the breast. Nevertheless, the survival benefit of surgical resection in patients with such lesions appears to be low, especially for low grade DCIS. Low-grade DCIS typically exhibit a slow growth pattern and, in many cases, never fully develop into a clinically significant disease: discerning harmless lesions from potentially invasive ones could lead to avoid overtreatment in many patients. Nonetheless, up to $26 \%$ of patients with biopsyproven DCIS can reveal a synchronous invasive carcinoma in surgical specimens. Here, we aimed to create a model of radiological and pathological criteria able to reduce the underestimation of vacuum assisted breast biopsy in DCIS. We have developed an easy to use predictive model of radiological and pathological criteria, in which, for patients with favourable features, the predicted probability of diagnostic underestimation was $1 \%$.

\footnotetext{
Abstract: Background: We aimed to create a model of radiological and pathological criteria able to predict the upgrade rate of low-grade ductal carcinoma in situ (DCIS) to invasive carcinoma, in patients undergoing vacuum-assisted breast biopsy (VABB) and subsequent surgical excision. Methods: 3100 VABBs were retrospectively reviewed among which we reported 295 low-grade DCIS who subsequently underwent surgery. The association between patients' features and the upgrade rate to invasive breast cancer (IBC) was evaluated by univariate analysis. Finally, we developed a predictive multivariable model based on the features which were significantly associated with the univariate analysis outcome. Results: the upgrade rate to invasive carcinoma was $10.8 \%$. At univariate analysis, the risk of upgrade was significantly lower in the absence of post- biopsy residual lesion $(p<0.001)$, age $>50(p=0.029)$, and in presence of low-grade DCIS only in specimens with microcalcifications $(\mathrm{p}=0.002)$. According to the final multivariable model, the predicted probability of
} 
diagnostic underestimation for a patient with all the three favourable features selected at univariate analysis was $1 \%$ (95\% CI: $0.3 \%-4 \%$ ). Conclusions: An easy to use predictive model of radiological and pathological criteria is able to identify patients with low-grade carcinoma in situ with low risk of upstaging to infiltrating carcinomas.

Keywords: ductal carcinoma in situ (DCIS); invasive breast carcinoma; breast; biopsy; overtreatment; active surveillance.

\section{Introduction}

Breast cancer is one of the most prevalent malignancies among women worldwide and yet leads to a considerable incidence of death, wherein 2020, almost 685000 women were deceased owing to this malignancy [1]. Ductal carcinoma in situ (DCIS) represents almost $20-25 \%$ of all breast neoplastic lesions diagnosed [2-3]. In DCIS, the cancer cells' growth is confined to the breast ducts or lobules with a minimal potential to spread [4].

As DCIS is mainly clinically occult (around $9 \%$ are symptomatic), more than $90 \%$ of cases are detected only through imaging studies. Prior to 1980, this condition could be rarely identified. Owing to the improvement of diagnostic and screening imaging tools, specifically mammography, DCIS incidence has rapidly increased [5].

According to the Current National Comprehensive Cancer Network (NCCN) the best therapeutic options are recommended as mastectomy, lumpectomy with radiation, or lumpectomy alone with the potential addition of tamoxifen for hormone receptor-positive carcinoma in situ [6]. There are few data available that compare the benefit obtained from the currently recommended treatments with those who did not receive treatment (active surveillance) [7].

Carcinoma in situ of the breast does not present a risk of invasion and metastasis and the mortality rate is as low as $4 \%$ [7]. Therefore, the main purpose of the treatment is to prevent the development of invasive carcinoma.

However, a meta-analysis of underestimation and predictors of invasive breast cancer showed that up to $26 \%$ of patients with biopsy-proven DCIS can reveal a synchronous invasive carcinoma in surgical specimens [8]. As this percentage is unacceptable, it is necessary to reduce the diagnostic underestimation of the VABB before proposing active surveillance to patients.

How many low-grade breast carcinomas in situ are actually infiltrating carcinomas or high-grade carcinomas in situ? How can we identify patients at low risk of being underestimated with the VABB?

The purpose of our study is to identify a predictive model that identifies the features mainly based on imaging, that can predict the diagnostic underestimation of low-grade DCIS to invasive carcinoma or worst grade DCIS. To reach this objective, we examined surgical specimens of patients diagnosed with low-grade DCIS to identify potential indicators for upgrading [9].

By selecting a population with a low risk of upgrading, we may identify patients with low-grade breast cancer in which surgery may be safely spared. 
Four prospective international study protocols (LORIS, COMET, LORD, and LORETTA) are currently in place to evaluate non-invasive treatment strategies for DCIS: however, a selection of patient population based on clinical and radiological features (which may reduce the diagnostic underestimation of the biopsy) appears neglected in these protocols [10]. Details are shown in Table 1.

Table 1. Main features of the four prospective international study protocols (LORIS, COMET, LORD and

\section{LORETTA).}

\begin{tabular}{|c|c|c|c|c|}
\hline Study & LORIS [11] & COMET [12] & LORD [13] & LORIS [14] \\
\hline Country & UK & USA & EU & JAPAN \\
\hline Year of activation & 2014 & 2017 & 2017 & 2017 \\
\hline $\begin{array}{l}\text { Accrual target (number of } \\
\text { patients) }\end{array}$ & 932 & 1200 & 1240 & 340 \\
\hline Size of the lesion & Any & Any & Any & $<2.5 \mathrm{~cm}$ \\
\hline Type of guide for biopsy & $\begin{array}{l}\text { Stereotactic (vacuum } \\
\text { assisted) }\end{array}$ & $\begin{array}{l}\text { Stereotactic (vacuum } \\
\text { assisted) }\end{array}$ & $\begin{array}{l}\text { Stereotactic (vacuum } \\
\text { assisted) }\end{array}$ & $\begin{array}{l}\text { Stereotactic and ul- } \\
\text { trasound (vacuum } \\
\text { assisted) }\end{array}$ \\
\hline Hormone receptor status & Any & Hr- positive only & Any & Hr positive only \\
\hline Endocrine therapy & optional & optional & Not allowed & mandatory \\
\hline Minimum age at diagnosis & 48 & 40 & 45 & 40 \\
\hline Comedonecrosis & excluded & allowed & excluded & excluded \\
\hline
\end{tabular}

\section{Materials and Methods}

This retrospective study was notified to the Ethics Committee (Identification Number UID 2897) and was approved by the Institutional Review Board.

Study design and population

We retrospectively studied all patients who underwent a screening mammogram or an ultrasound for prevention, i.e. dense breasts in a single referral center for breast cancer care (European Institute of Oncology, Milan, Italy). Among which those with doubtful lesions, between January 1999 and January 2019, were included in our study cohort. All the lesions were classified according to the Breast Imaging Reporting and Data System (BI-RADS), using the score BIRADS $\geq 3$ as a threshold to define suspicious lesion. Ultrasound- or stereotactic-guided VABB was performed in patients with BIRADS $\geq 4$; only in exceptional cases (3/295), with very high familiarity for breast cancer, patients with BIRADS 3 were biopsied too [15-17].

All the lesions undergoing stereotactic VABB presented as microcalcifications. Before each stereotactic VABB, two projection mammograms were performed in order to assess the precise extension of the lesion (figure 1). 


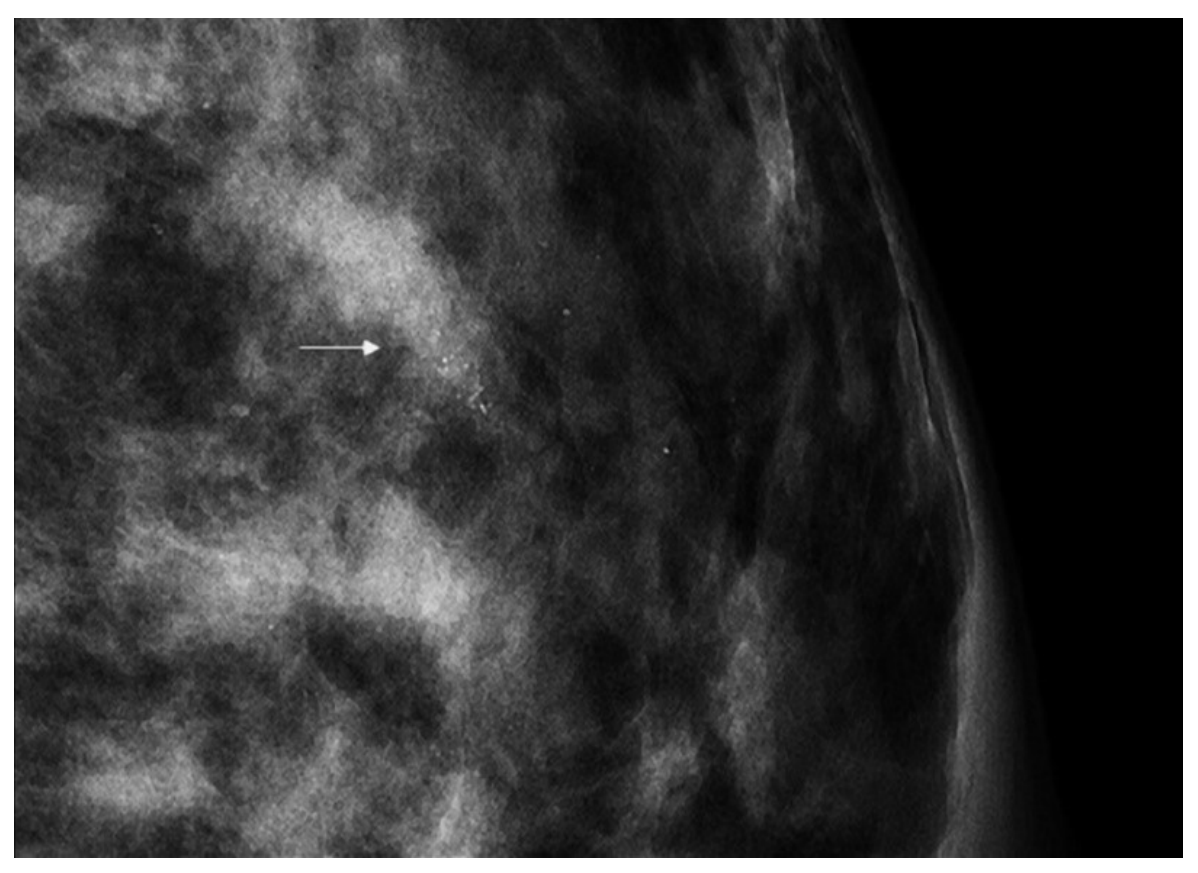

Figure 1. Full field digital mammography showing a small cluster of pleomorphic microcalcifications (arrow) with a biopsy-proven histopathological result of low-grade ductal carcinoma in situ.

After the VABB procedure, all patients underwent two additional mammogram projections to confirm the complete macroscopic removal or the presence of residual lesion.

Before each ultrasound VABB, both transverse and longitudinal static images were acquired by US performed prior to the biopsy. After the procedure both transverse and longitudinal US images were taken to detect the complete macroscopic removal or the presence of residual of the lesion in all patients.

We collected and retrospectively analysed some of the features reported in the radiologist's and pathologist's report, in particular: the number of cores obtained for each biopsy, the complete macroscopical removal of the lesion, the diameter of the biopsy needle, and - for stereotactic VABB- if the disease was present only in the cores with microcalcifications (or even in the cores without microcalcifications, if any).

We investigated a potential correlation between patient's age, lesion size, diameter of the needle, number of cores, complete macroscopic removal of the lesion, cases showing low grade DCIS only in cores with microcalcifications, and the chance of upgrade to a worst grade DCIS or invasive ductal carcinoma (IDC). Since the BIRADS is often very subjective [18], we have excluded it from the analysis. Figure 2 represents a low-grade DCIS. 


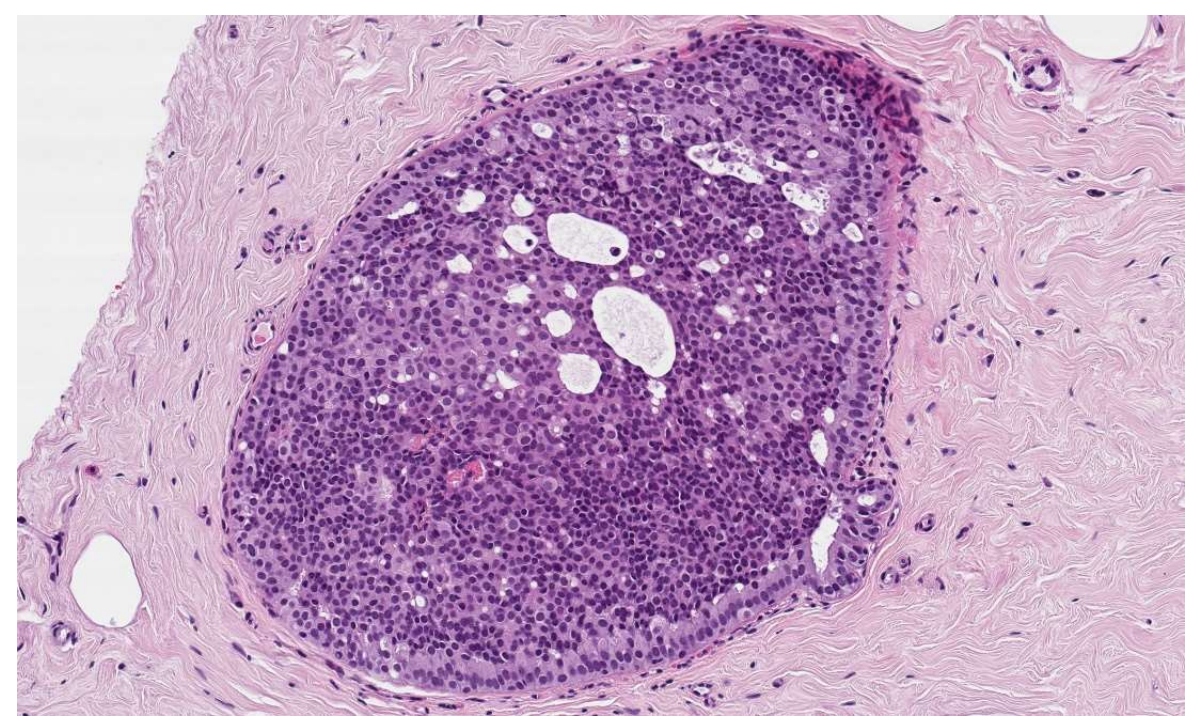

Figure2. Histological features of low-grade DCIS from a breast biopsy showing bland homogeneous cells contained within the duct, forming rigid cell 'bridges' across the duct space in a cribriform architecture. In this case, the abnormal duct is surrounded by fibrotic stroma. (hematoxylin and eosin, original magnification 100x).

In accordance with some recent studies that have shown a benefit in the change of therapy with patients presenting an intermediate grade DCIS with Ki-67 > 14\%, we considered this threshold to be significant in our underestimation analyses of worst grade carcinoma in situ at the biopsy [19]. In our predictive model we also considered as underestimation to carcinoma in situ of worst degree in case of finding of intermediate grade DCIS with Ki-67> $14 \%$.

\section{Statistical Analysis}

Continuous data are reported as median and range, categorical data are reported as counts and percentages.

Univariate logistic regressions were performed to assess the association of age, biopsy needle, residual disease, number of cores and disease only in cores with micro, with the risk of upgrade of low-grade DCIS to invasive carcinoma.

The variables with $\mathrm{P}<0.05$ at univariate analysis were included in a multivariable logistic regression model, and the predicted probabilities of upstage were obtained according to the model.

All analyses were performed with SAS 9.4 (SAS Institute, Cary, NC).

\section{Results}

Among the 3100 VABBs analysed, 295 were diagnosed as low-grade DCIS and all the patients underwent subsequent surgical excision.

The clinicopathological features of the patients are summarized in Table 2.

Table 2. Distribution of patients, diagnostic and tumor characteristics ( $N=295$ DCIS low grade) 


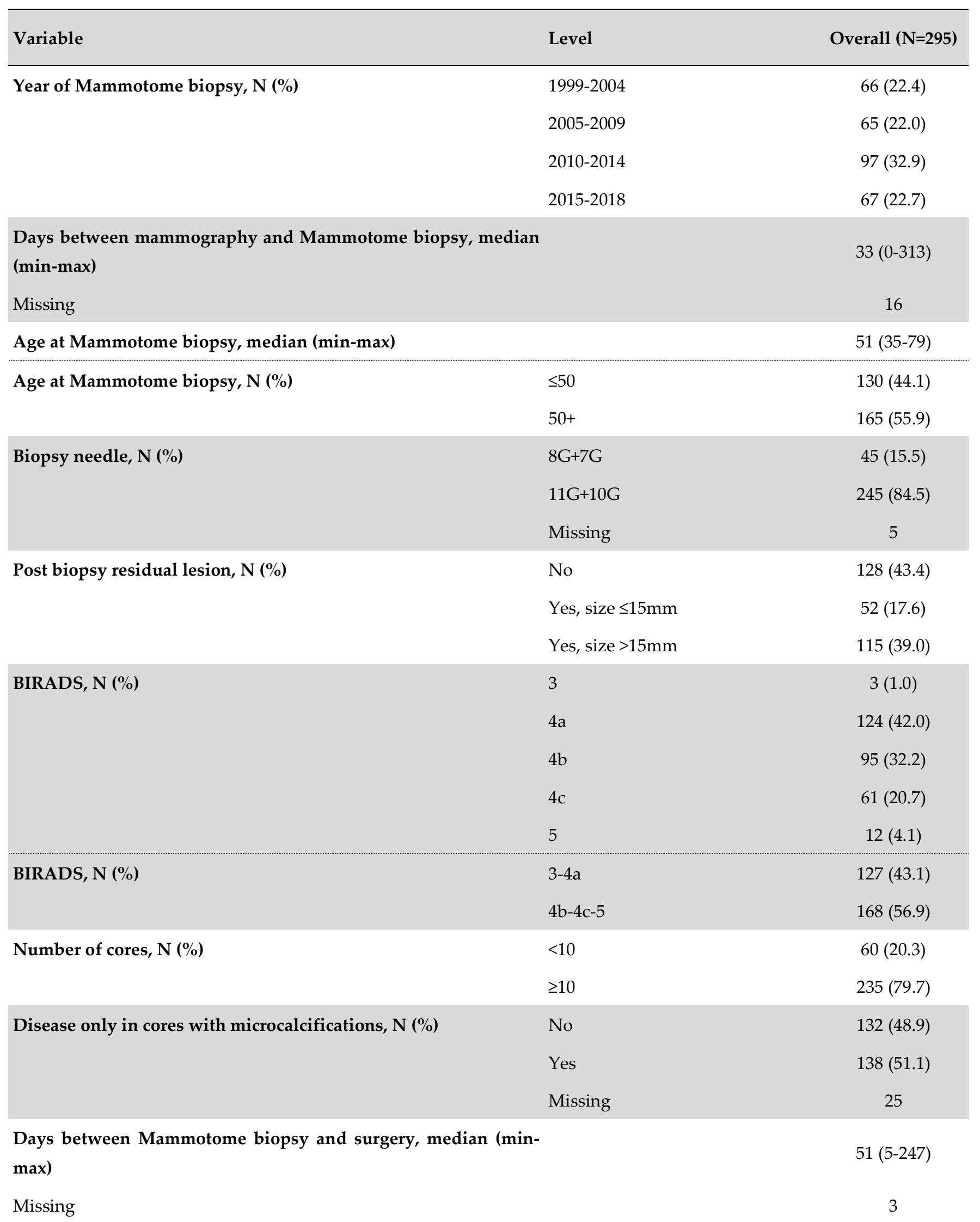




\begin{tabular}{llc}
\hline Variable & Level & Overall (N=295) \\
\hline Outcomes of the study & & $263(89.2)$ \\
\hline Upstage (invasive at surgery), N (\%) & No & $32(10.8)$ \\
\hline Upstage (implying change of therapy), N (\%) & Yes & $242(82.0)$ \\
\hline Absence of disease at the surgery, N (\%) & No & $53(18.0)$ \\
\hline
\end{tabular}

Of these 295 patients, 272 were diagnosed by stereotactic VABB and identified by mammography (showing only microcalcifications), while 23 cases were diagnosed by ultrasound-guided VABB (showing as nodule).

Such disproportion is due to the usual radiological manifestation of DCIS as microcalcifications, instead of nodules [20].

At the biopsy, the median age of patients was 51 (35-79) years, the median size of the lesion was 15mm (4-100); Radiological diagnoses were: 3 BIRADS 3 (1\%); 124 BIRADS 4a (42\%); 95 BIRADS 4b (32.2\%); 61 BIRADS 4c (20.7\%); 12 BIRADS 5 (4.1\%).

In 128 (43.4\%) of cases the lesion was macroscopically removed by VABB. In 138 cases $(51.1 \%)$ we identified the disease only in the cores with macrocalcifications.

The histological exam of the surgical specimens of the 295 patients indicated that 32 cases $(10.8 \%)$ were upgraded to IDC, and 53 cases $(18.0 \%)$ were upgraded to worst grade DCIS, intermediate grade DCIS with Ki-67>14\% and, high-grade ductal carcinoma in situ.

Interestingly, in 61 cases $(20.7 \%)$ only benign findings were observed in subsequent surgical specimens: in some cases, the VABB seems to be able to completely remove the lesion.

The upgrade rate to IDC was statistically lower at univariate analysis considering: the complete removal of the lesion (OR $(95 \% \mathrm{CI})$ for size $\leq 15 \mathrm{~mm}$ and size $>15 \mathrm{~mm}$ vs. no residual disease were 5.43 (1.31-22.6) and 10.4 (3.04-35.7), respectively); age of the patients (OR $(95 \% \mathrm{CI})$ for patients with more than 50 years vs. less than 50 years was $0.43(0.20-$ $0.92)$ ) and the presence of low grade DCIS only in specimens with microcalcifications (OR (95\% CI) equal to $0.24(0.10-0.58)$.

Including these patients' characteristics, which were statistically significant as independent variables, in a multivariable model, post biopsy residual lesion and the disease also in cores without microcalcifications maintained a statistically significant association with the risk of upstage (table 3). 
Table 3. Association between variables and upstage to invasive carcinoma (invasive at surgery)

\begin{tabular}{|c|c|c|c|c|c|c|c|c|}
\hline \multirow{2}{*}{ Variable } & \multirow{2}{*}{ Level } & \multirow{2}{*}{$\begin{array}{c}\text { Upstage to } \\
\text { invasive } \\
\text { carcinoma / Total } \\
\text { (\%) }\end{array}$} & \multicolumn{3}{|c|}{ Univariate analysis } & \multicolumn{3}{|c|}{ Multivariable analysis ${ }^{12}$} \\
\hline & & & OR & $95 \%$ CI & P-value & OR & $95 \%$ CI & P-value \\
\hline Overall & - & 32/295 (10.8) & - & - & - & - & - & - \\
\hline \multirow[t]{2}{*}{$\begin{array}{l}\text { Age at Mammotome } \\
\text { biopsy }\end{array}$} & $\leq 50$ & 20/130 (15.4) & Ref. & - & - & Ref. & - & - \\
\hline & $50+$ & $12 / 165(7.3)$ & 0.43 & $0.20-0.92$ & 0.029 & 0.56 & $0.25-1.26$ & 0.16 \\
\hline \multirow[t]{3}{*}{ Biopsy needle } & $8 \mathrm{G}+7 \mathrm{G}$ & $7 / 45$ (15.6) & Ref. & - & - & & & \\
\hline & $11 G+10 G$ & 25/245 (10.2) & 0.62 & $0.25-1.53$ & 0.30 & & & \\
\hline & Missing & $0 / 5$ & & & & & & \\
\hline \multirow{3}{*}{$\begin{array}{l}\text { Post biopsy residual } \\
\text { lesion }\end{array}$} & No & $3 / 128(2.3)$ & Ref. & - & - & Ref. & - & - \\
\hline & Yes, size $\leq 15 \mathrm{~mm}$ & 6/52 (11.5) & 5.43 & $1.31-22.6$ & 0.020 & 4.41 & $0.99-19.6$ & 0.051 \\
\hline & Yes, size $>15 \mathrm{~mm}$ & 23/115 (20.0) & 10.4 & $3.04-35.7$ & $<0.001$ & 7.54 & $2.14-26.6$ & 0.002 \\
\hline \multirow[t]{2}{*}{ Number of cores } & $<10$ & 7/60 (11.7) & Ref. & - & - & & & \\
\hline & $\geq 10$ & 25/235 (10.6) & 0.90 & $0.37-2.20$ & 0.82 & & & \\
\hline \multirow{3}{*}{$\begin{array}{l}\text { Disease only in cores } \\
\text { with } \\
\text { microcalcifications }\end{array}$} & No & 24/132 (18.2) & Ref. & - & - & Ref. & - & - \\
\hline & Yes & $7 / 138(5.1)$ & 0.24 & $0.10-0.58$ & 0.002 & 0.35 & $0.14-0.88$ & 0.025 \\
\hline & Missing & $1 / 25$ & & & & & & \\
\hline
\end{tabular}

1. Only variables with $\mathrm{P}<0.05$ at univariate analysis were included in multivariable model.

2. 270 patients (31 events) were included in multivariable analysis (patients with at least one missing value among independent variables were excluded) 
Table 4. Predicted probabilities of upstage (invasive at surgery), according to the multivariable logistic regression model

\begin{tabular}{|c|c|c|c|}
\hline $\begin{array}{l}\text { Age at Mammotome } \\
\text { biopsy }\end{array}$ & Residual lesion & $\begin{array}{l}\text { Disease only in cores } \\
\text { with } \\
\text { microcalcifications }\end{array}$ & $\begin{array}{l}\text { Upstaging } \\
\text { probability }(95 \% \mathrm{CI})\end{array}$ \\
\hline \multirow[t]{6}{*}{$\leq 50$} & No & No & $0.06(0.02-0.18)$ \\
\hline & & Yes & $0.02(0.01-0.08)$ \\
\hline & Yes, size $\leq 15 \mathrm{~mm}$ & No & $0.22(0.09-0.45)$ \\
\hline & & Yes & $0.09(0.03-0.24)$ \\
\hline & Yes, size $>15 \mathrm{~mm}$ & No & $0.32(0.21-0.46)$ \\
\hline & & Yes & $0.14(0.06-0.30)$ \\
\hline \multirow[t]{6}{*}{$50+$} & No & No & $0.03(0.01-0.11)$ \\
\hline & & Yes & $0.01(0.003-0.04)$ \\
\hline & Yes, size $\leq 15 \mathrm{~mm}$ & No & $0.13(0.05-0.32)$ \\
\hline & & Yes & $0.05(0.02-0.15)$ \\
\hline & Yes, size $>15 \mathrm{~mm}$ & No & $0.21(0.12-0.35)$ \\
\hline & & Yes & $0.08(0.03-0.20)$ \\
\hline
\end{tabular}

For example, in case of patients with more than 50 years, with complete removal of the lesion and lesions only in cores with microcalcifications, the probability of diagnostic underestimation of invasive carcinoma was $1 \%(0.3 \%-4 \%)$.

\section{DISCUSSION}

DCIS is a non-life threatening condition and includes about $25 \%$ cases of all breast cancer cases. Most of DCIS will never progress to invasive breast cancer during a patient's lifetime and the 20-year breast cancer-specific mortality rate in patients with DCIS is low [21-23].

Sagara and colleagues (7) in a recent publication analysed surveillance, epidemiology, and end-results (SEER) data from 9 US states involving 57222 women with a median 72 months' follow-up from diagnosis: the vast majority of patients diagnosed with all 
grades of DCIS (who did not receive surgery) did not decease from breast cancer. Considering this low long-term mortality, the surgical therapy and the radiotherapy of DCIS may be considered a sort of overtreatment and an unjustified cost to public health, especially for low-grade carcinomas in situ [24].

Four prospective international study protocols (LORIS, COMET, LORD, and LORETTA) are currently in place to evaluate non-invasive treatment strategies for DCIS the results of which will still be evaluated. However, the role of diagnostic underestimation of the breast biopsy is often overlooked. In a meta-analysis, Brennan et al. showed that $25.9 \%$ (18.6-37.2\%) of presurgical cases diagnosed as DCIS were upgraded to IDC upon excision (8). Considering only those undergoing VABB, this percentage dropped to around the $15 \%$ (regardless of the degree of DCIS) and to the $10 \%$ for the low-grade DCIS [2526]. This percentage is still too high to propose active surveillance to a patient, as follow-up over surgery should be justified by an upgrade rate lower than $2 \%$, as established for Breast Imaging Reporting and Data System, in which a possible diagnostic delay does not affect the outcome [27].

In our study, we propose a predictive model in order to minimize the risk of diagnostic underestimation in a smaller group of patients. Nomograms are predictive tools that allow, considering the multiples features, an assessment of the risk of underestimation [28]. In our predictive model in case of complete removal of the lesion, with lesions under $15 \mathrm{~mm}$ and lesions only in cores with microcalcifications, the probability of diagnostic underestimation of IDC drops below $2 \%$. Notably, in almost $20 \%$ of those who underwent surgery, no residual of disease was found in the surgical sample, suggesting a possible complete lesion removal by the VABB.

We believe that our predictive model, once validated in an external cohort, could help in the careful selection of patients to candidate to active surveillance rather than surgical excision. Our study may pose the basis for further future prospective studies where active surveillance can be suggested considering specific radiological and pathological criteria.

Our predictive model could also be associated with genetic parameters that can further help in the identification of patients at low risk of upstaging and local recurrence risk [29]. The major limitation of our study is represented by its monocentric and retrospective nature, by the relatively low number of cases considered, and by the lack of an external validation cohort.

\section{CONCLUSION}

An easy to use predictive model that considers the size of the lesion, its complete removal with $\mathrm{VABB}$ and the presence of disease only in cores with microcalcifications is able to identify a population of patients with DCIS with low risk of upstaging to IDC.

These criteria, after validation in an external cohort, should be considered when selecting patients for active surveillance rather than surgical intervention. 
Author Contributions: Conceptualization, L.N. and F.P.; methodology, A.B. , S.P., C.T, M.P.; software, V.B., S.F.; validation, A.B, P.V., G.L. ,G.L, and E.C.; formal analysis, S.F. and V.B.; investigation, L.N, F.P; resources, A.L., M.M. and M.L.; data curation, C.F., S.F. and V.B.; writing - original draft preparation, L.N. F.P. and E.C.; writing-review and editing, N.F., E.S. and M.L., visualization, M.L, N.F, and E.S.; supervision, L.N. and F.P.; project administration, M.L and E.C. All authors have read and agreed to the published version of the manuscript

Funding: This research received no external funding.

Institutional Review Board Statement: The study was conducted according to the guidelines of the Declaration of Helsinki, and approved by the Ethics Committees of European Institute of Oncology (IEO, protocol code UID 2897, 24.09.2021)

Informed Consent Statement: Informed consent was obtained from all subjects involved in the study

Data Availability Statement: The data presented in this study are available on request from the corresponding author. The data are not publicly available due to privacy concerns, in accordance with GDPR.

Conflicts of Interest: The authors declare no conflict of interest.

\section{BIBLIOGRAPHY:}

1. Sung H, Ferlay J, Siegel RL, Laversanne M, Soerjomataram I, Jemal A, Bray F. Global Cancer Statistics 2020: GLOBOCAN Estimates of Incidence and Mortality Worldwide for 36 Cancers in 185 Countries. CA Cancer J Clin. 2021 May;71(3):209-249. doi: 10.3322/caac.21660. Epub 2021 Feb 4. PMID: 33538338.

2. Kerlikowske K. Epidemiology of ductal carcinoma in situ. J Natl Cancer Inst Monogr. 2010;2010(41):139-41. doi: 10.1093/jncimonographs/lgq027. PMID: 20956818; PMCID: PMC5161058.

3. Salvatorelli L, Puzzo L, Vecchio GM, Caltabiano R, Virzì V, Magro G. Ductal Carcinoma In Situ of the Breast: An Update with Emphasis on Radiological and Morphological Features as Predictive Prognostic Factors. Cancers (Basel). 2020 Mar 6;12(3):609. doi: 10.3390/cancers12030609. PMID: 32155777; PMCID: PMC713961

4. Parikh U, Chhor CM, Mercado CL. Ductal Carcinoma In Situ: The Whole Truth. AJR Am J Roentgenol. 2018 Feb;210(2):246-255. doi: 10.2214/AJR.17.18778. Epub 2017 Oct 18. PMID: 29045181.

5. D'Orsi CJ. Imaging for the diagnosis and management of ductal carcinoma in situ. J Natl Cancer Inst Monogr. 2010;2010(41):214-217. doi:10.1093/jncimonographs/lgq037

6. Wehner P, Lagios MD, Silverstein MJ. DCIS treated with excision alone using the National Comprehensive Cancer Network (NCCN) guidelines. Ann Surg Oncol. 2013 Oct;20(10):3175-9. doi: 10.1245/s10434-013-3176-2. Epub 2013 Aug 22. PMID: 23975306.

7. Sagara Y, Mallory MA, Wong S, Aydogan F, DeSantis S, Barry WT, Golshan M. Survival Benefit of Breast Surgery for Low-Grade Ductal Carcinoma In Situ: A Population- 
Based Cohort Study. JAMA Surg. 2015 Aug;150(8):739-45. doi: 10.1001/jamasurg. 2015.0876. Erratum in: JAMA Surg. 2015 Aug;150(8):820. PMID: 26039049.

8. Brennan ME, Turner RM, Ciatto S, Marinovich ML, French JR, Macaskill P, Houssami N. Ductal carcinoma in situ at core-needle biopsy: meta-analysis of underestimation and predictors of invasive breast cancer. Radiology. 2011 Jul;260(1):119-28. doi: 10.1148/radiol.11102368. Epub 2011 Apr 14. PMID: 21493791.

9. Veronesi U, Viale G, Rotmensz N, Goldhirsch A. Rethinking TNM: breast cancer TNM classification for treatment decision-making and research. Breast. 2006 Feb;15(1):38. doi: 10.1016/j.breast.2005.11.011. PMID: 16473737.

10. Kanbayashi, C.; Thompson, A.M.; Hwang, E.S.; Partridge, A.H.; Rea, D.W.; Wesseling, J.; Shien, T.; Mizutani, T.; Shibata, T.; Iwata, H. The international collaboration of active surveillance trials for low-risk DCIS (LORIS, LORD, COMET, LORETTA). J. Clin. Oncol. 2019, 37 (Suppl. 15), TPS603

11. Francis A, Thomas J, Fallowfield L, Wallis M, Bartlett JM, Brookes C, Roberts T, Pirrie S, Gaunt C, Young J, Billingham L, Dodwell D, Hanby A, Pinder SE, Evans A, Reed M, Jenkins V, Matthews L, Wilcox M, Fairbrother P, Bowden S, Rea D. Addressing overtreatment of screen detected DCIS; the LORIS trial. Eur J Cancer. 2015

Nov;51(16):2296-303. doi: 10.1016/j.ejca.2015.07.017. Epub 2015 Aug 18. PMID: 26296293.

12. Hwang ES, Hyslop T, Lynch T, Frank E, Pinto D, Basila D, Collyar D, Bennett A, Kaplan C, Rosenberg S, Thompson A, Weiss A, Partridge A. The COMET (Comparison of Operative versus Monitoring and Endocrine Therapy) trial: a phase III randomised controlled clinical trial for low-risk ductal carcinoma in situ (DCIS). BMJ Open. 2019 Mar 12;9(3):e026797. doi: 10.1136/bmjopen-2018-026797. PMID: 30862637; PMCID: PMC6429899.

13. Elshof LE, Tryfonidis K, Slaets L, van Leeuwen-Stok AE, Skinner VP, Dif N, Pijnappel RM, Bijker N, Rutgers EJ, Wesseling J. Feasibility of a prospective, randomised, open-label, international multicentre, phase III, non-inferiority trial to assess the safety of active surveillance for low risk ductal carcinoma in situ - The LORD study. Eur J Cancer. 2015 Aug;51(12):1497-510. doi: 10.1016/j.ejca.2015.05.008. Epub 2015 May 26. PMID: 26025767

14. Kanbayashi C, Iwata H. Current approach and future perspective for ductal carcinoma in situ of the breast. Jpn J Clin Oncol. 2017 Aug 1;47(8):671-677. doi: 10.1093/jjco/hyx059. PMID: 28486668; PMCID: PMC5896693.

15. American College of Radiology

ACR BI-RADS atlas: breast imaging reporting and data system

(5th ed.), Reston, Virginia (2013).

16. American College of Radiology. ACR BI-RADS 5th edition changes. http://www.acr.org/ /media/acr/documents/pdf/qualitysafety/resources/birads/birads_v5_changes.pdf [accessed on 01.01.17].

17. Spak DA, Plaxco JS, Santiago L, Dryden MJ, Dogan BE. BI-RADS® fifth edition: A summary of changes. Diagn Interv Imaging. 2017 Mar;98(3):179-190. doi: 10.1016/j.diii.2017.01.001. Epub 2017 Jan 25. PMID: 28131457. 
18. Spayne MC, Gard CC, Skelly J, Miglioretti DL, Vacek PM, Geller BM. Reproducibility of BI-RADS breast density measures among community radiologists: a prospective cohort study. Breast J. 2012;18(4):326-333. doi:10.1111/j.1524-4741.2012.01250.x

19. Lazzeroni M, Guerrieri-Gonzaga A, Botteri E, Leonardi MC, Rotmensz N, Serrano D, Varricchio C, Disalvatore D, Del Castillo A, Bassi F, Pagani G, DeCensi A, Viale G, Bonanni B, Pruneri G. Tailoring treatment for ductal intraepithelial neoplasia of the breast according to Ki-67 and molecular phenotype. Br J Cancer. 2013 Apr 30;108(8):1593-601. doi: 10.1038/bjc.2013.147. Epub 2013 Apr 11. PMID: 23579208; PMCID: PMC366847

20. Wang H, Lin J, Lai J, Tan C, Yang Y, Gu R, Jiang X, Liu F, Hu Y, Su F. Imaging features that distinguish pure ductal carcinoma in situ (DCIS) from DCIS with microinvasion. Mol Clin Oncol. 2019 Sep;11(3):313-319. doi: 10.3892/mco.2019.1891. Epub 2019 Jul 3. PMID: 31396390; PMCID: PMC6667913.

21. Molinié F, Vanier A, Woronoff AS, Guizard AV, Delafosse P, Velten M, DaubisseMarliac L, Arveux P, Tretarre B. Trends in breast cancer incidence and mortality in France 1990-2008. Breast Cancer Res Treat. 2014 Aug;147(1):167-75. doi: 10.1007/s10549014-3073-9. Epub 2014 Aug 9. PMID: 25106658.

22. Narod SA, Iqbal J, Giannakeas V, Sopik V, Sun P. Breast Cancer Mortality After a Diagnosis of Ductal Carcinoma In Situ. JAMA Oncol. 2015 Oct;1(7):888-96. doi: 10.1001/jamaoncol.2015.2510. PMID: 26291673.

23. Lazzeroni M, DeCensi A. De-Escalating Treatment of Low-Risk Breast Ductal Carcinoma In Situ. J Clin Oncol. 2020 Apr 20;38(12):1252-1254. doi: 10.1200/JCO.20.00124. Epub 2020 Mar 3. PMID: 32125939.

24. Fallowfield L, Francis A. Overtreatment of Low-Grade Ductal Carcinoma In Situ. JAMA Oncol. 2016 Mar;2(3):382-3. doi: 10.1001/jamaoncol.2015.5026. PMID: 26720092.

25. Nicosia L, di Giulio G, Bozzini AC, Fanizza M, Ballati F, Rotili A, Lazzeroni M, Latronico A, Abbate F, Renne G, Addante F, Lucioni M, Cassano E, Mastropasqua MG. Complete Removal of the Lesion as a Guidance in the Management of Patients with Breast Ductal Carcinoma In Situ. Cancers (Basel). 2021 Feb 18;13(4):868. doi: 10.3390/cancers13040868. PMID: 33670739; PMCID: PMC7923077.

26. Cheung YC, Chen SC, Ueng SH, Yu CC. Ductal Carcinoma In Situ Underestimation of Microcalcifications Only by Stereotactic Vacuum-Assisted Breast Biopsy: A New Predictor of Specimens without Microcalcifications. J Clin Med. 2020 Sep 17;9(9):2999. doi: 10.3390/jcm9092999. PMID: 32957459; PMCID: PMC7565646.

27. Sickles, E.A., D’Orsi, C.J., Bassett, L.W., et al. (2013) ACR BI-RADS Mammography. In: ACR BI-RADS Atlas, Breast Imaging Reporting and Data System, 5th Edition, American College of Radiology, Reston, VA, 134-136.

28. Nicosia L, Latronico A, Addante F, De Santis R, Bozzini AC, Montesano M, Frassoni S, Bagnardi V, Mazzarol G, Pala O, Lazzeroni M, Lissidini G, Mastropasqua MG, Cassano E. Atypical Ductal Hyperplasia after Vacuum-Assisted Breast Biopsy: Can We Reduce the Upgrade to Breast Cancer to an Acceptable Rate? Diagnostics (Basel). 2021 Jun 19;11(6):1120. doi: 10.3390/diagnostics11061120. PMID: 34205428; PMCID: PMC825951 
29. Solin LJ, Gray R, Baehner FL, Butler SM, Hughes LL, Yoshizawa C, Cherbavaz DB, Shak S, Page DL, Sledge GW Jr, Davidson NE, Ingle JN, Perez EA, Wood WC, Sparano JA, Badve S. A multigene expression assay to predict local recurrence risk for ductal carcinoma in situ of the breast. J Natl Cancer Inst. 2013 May 15;105(10):701-10. doi: 10.1093/jnci/djt067. Epub 2013 May 2. PMID: 23641039; PMCID: PMC3653823. 
